\title{
Current and emerging therapeutic options for the treatment of chronic chagasic cardiomyopathy
}

This article was published in the following Dove Press journal:

Vascular Health and Risk Management

13 July 2010

Number of times this article has been viewed

\author{
Claudio A Muratore' \\ Adrian Baranchuk ${ }^{2}$ \\ 'Department of Cardiology, \\ Arrhythmia Service, Hospital \\ Fernandez, Buenos Aires, Argentina; \\ ${ }^{2}$ Department of Cardiology, \\ Arrhythmia Service, Kingston General \\ Hospital, Kingston, Ontario, Canada
}

Correspondence: Claudio A Muratore Pedro Moran 3538, Buenos Aires, Argentina (CP 1419) Tel 0054 I | 45043722

Fax 0054-I I 48985799

Email cmuratore@intramed.net
Abstract: Chagas' disease is an endemic disease in Latin America caused by a unicellular parasite (Trypanosoma cruzi) that affects almost 18 million people. This condition involves the heart, causing heart failure, arrhythmias, heart block, thromboembolism, stroke, and sudden death. In this article, we review the current and emerging treatment of Chagas' cardiomyopathy focusing mostly on management of heart failure and arrhythmias. Heart failure therapeutical options including drugs, stem cells and heart transplantation are revised. Antiarrhythmic drugs, catheter ablation, and intracardiac devices are discussed as well. Finally, the evidence for a potential role of specific antiparasitic treatment for the prevention of cardiovascular disease is reviewed.

Keywords: chronic chagasic cardiomyopathy, emerging therapeutic options

Chagas' disease is an endemic disease in Latin America caused by a unicellular parasite, Trypanosoma cruzi. Almost 18 million people are infected ${ }^{1}$ and almost $25 \%$ of them will develop chronic myocardial disease in the following years or decades. The intermediate phase of the disease, also known as "undetermined phase" (currently a term under review, given the fact that several physiopathological mechanisms occur during this phase) may last for two to three decades, and the only "detectable" manifestation of the disease is the immunological reaction and some degree of autonomic dysfunction. Approximately $30 \%$ of the infected patients will develop end organ disease (cardiac, gastrointestinal, and neurological). ${ }^{2}$

Although a marked decrease in the incidence has been observed in the last decade it is still a major health problem in many countries of Latin America. In 2005, the genome sequence of Trypanosoma cruzi was finally discovered, initiating a new era of Chagas' disease treatment based on targeting specific protein kinases and phosphatases. ${ }^{3}$ Chronically infected individuals may develop, after the asymptomatic period, chronic myocarditis (Figure 1, Panels A and B) and less frequently megacolon, megaesophagus, or neurological afflictions. ${ }^{2,4}$

The main causes of death associated with chronic Chagas' cardiomyopathy $(\mathrm{CChC})$ are progressive congestive heart failure and sudden cardiac death. ${ }^{5,6}$ Although malignant ventricular arrhythmias are thought to be the main cause of sudden death, bradyarrhythmias, and thrombo-embolic events account for some of the sudden death as well. ${ }^{7,8}$

Chagas' disease has become a worldwide problem, given the new patterns of immigration. Physicians around the world should become aware of its existence and how to recognize and treat it. ${ }^{9}$ This review is intended to revise the current therapeutical options for the treatment of heart failure and ventricular arrhythmias associated with $\mathrm{CChC}$. submit your manuscript | www.dovepress.com

Dovepress

8355 


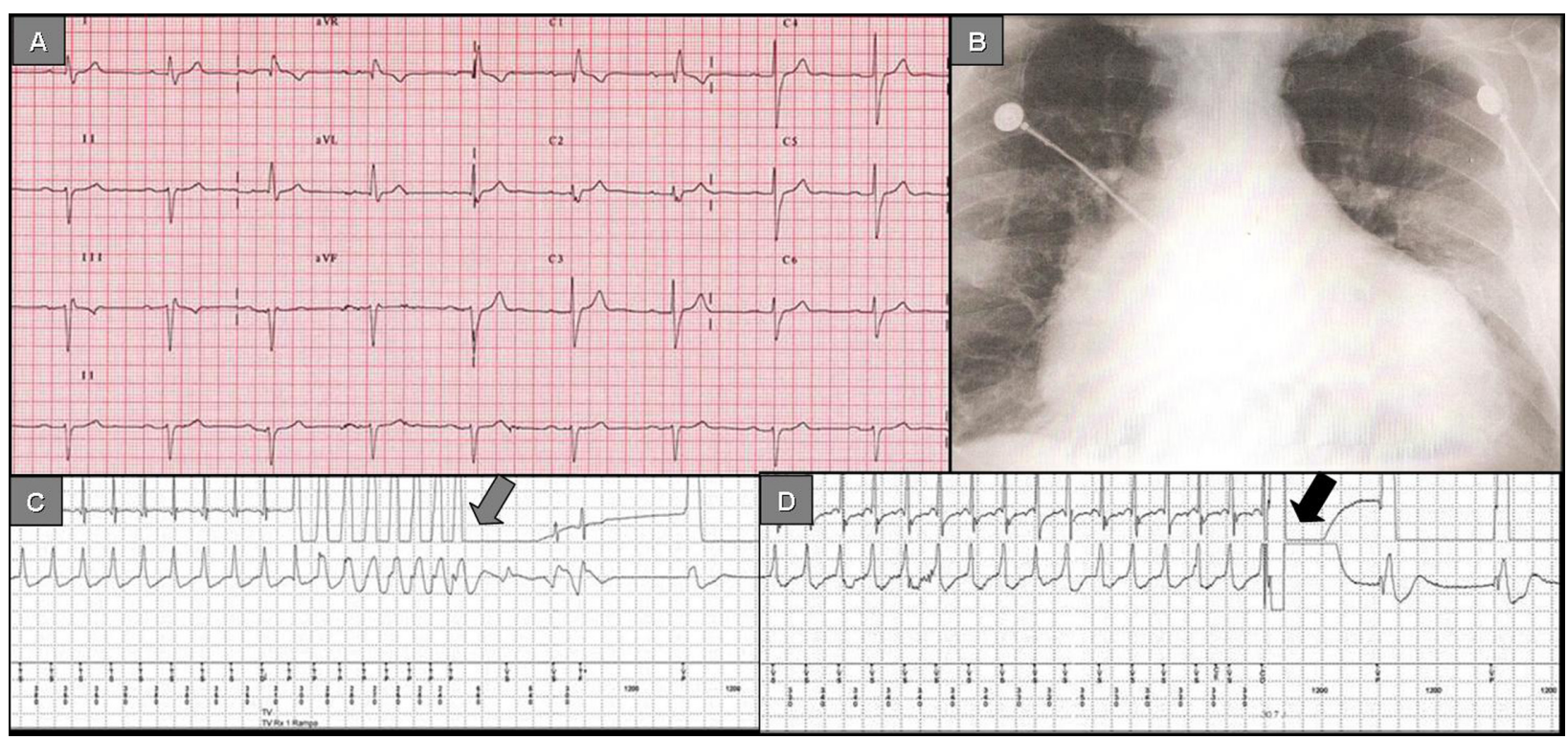

Figure I Panel A) 12-lead ECG depicting the typical conduction disorders associated with Chagas' disease: Right bundle branch block, left anterior fascicular block, $1{ }^{\circ}$ AV block. Panel B) Chest X-ray (antero-posterior view): Increased cardiothoracic index, vascular cephalization. Panel C) ICD stored electrogram depicts VT successfully terminated by antitachycardia pacing (grey arrow). Panel D) ICD stored electrogram depicts VT successfully terminated by a shock (black arrow).

\section{Methods}

We reviewed the literature on the current epidemiologic data, pathophysiology, and classic and emerging therapeutic options for Chagas' disease. Articles were selected from a computerized literature search in the Medline and Scielo databases using the keywords: "Chagas", "Chagas' disease", "Chagas' cardiomyopathy", "Chagasic disease", "heart failure", "antiarrhythmic drugs", "radiofrequency ablation", "pacemakers", "implantable cardioverter defibrillators", "stem cells", and "heart transplantation"; and all the possible combinations of the above. Two independent investigators $(\mathrm{CM}, \mathrm{AB})$ reviewed the abstracts and selected the ones considered of interest for the review. Discrepancies were resolved by consensus. Personal communications with experts were included as well as free access database data gained on the Internet. The initial search showed 10,393 articles. The combination of keywords narrowed this number down to 1,234 . We selected 127 abstracts of which 76 were included in this review. The rest of the references were abstracts from proceeding books, book chapters, Internet databases, and personal communications.

\section{Current options for the treatment of chronic chagasic cardiomyopathy \\ Congestive heart failure treatment}

In $\mathrm{CChC}$, the hemodynamic and neurohormonal responses do not differ from those in other cardiomyopathies; treatment of congestive heart failure does not differ either. Usual therapeutic strategies such as diuretics, beta blockers, angiotensin-converting enzyme inhibitors, and spironolactone are likely as important in Chagas' disease as in other heart failure syndromes. ${ }^{10-13}$ Botoni et al found improvements in systolic and diastolic function as well as with the neurohormonal parameters using enalapril and spironolactone. ${ }^{13}$ This was consistent with results gained by Roberti et al. ${ }^{10}$ No impact on mortality was reported for patients with Chagas' disease.

Beta blockers have been avoided in patients with $\mathrm{CChC}$ disease because of bradyarrhyhmias and atrioventricular (AV) conduction defects. Botoni et $\mathrm{a} \mathrm{l}^{13}$ have shown in a double blind, placebo-controlled, and randomized trial including 42 patients with $\mathrm{CChC}$ that optimization of treatment with enalapril and spironolactone and subsequent addition of carvedilol were safe, hemodynamically well tolerated, and associated with an improvement in cardiac function and clinical status. In a recently published study, Issa et al ${ }^{14}$ examined the patients included in the REMADHE trial (prospective, randomized, single-center open parallel trial; designed to compare a disease management program versus control in patients with chronic heart failure). Patients were grouped according to the etiology of the cardiomyopathy (Chagas' disease versus non-Chagas' disease) and presence of beta blocker therapy. A total of 456 patients were included in the study. CChC was the etiology in 68 patients (14.9\%). In chagasic patients beta blocker were used less frequently (35.8\% versus $68 \%$; $P<0.001)$. In patients treated with beta blockers the survival of patients with Chagas' disease was similar to that of other 
etiologies. Beta blockers (HR 0.37, 95\% CI: 0.14 to 0.97 ; $P<0.044)$ were associated with better survival.

\section{Antiarrhythmic treatment in Chagas' disease Arrhythmias in Chagas' disease}

A wide spectrum of atrial and ventricular arrhythmias and conduction disturbances are frequently observed in patients with CChC. ${ }^{2,15,16}$ Sinus node and AV node dysfunction (binodal disease) are quite frequent. The most frequent manifestation is, by far, persistent sinus bradycardia (with or without AV dissociation). Sino-atrial block and sinus arrest are also observed as a manifestation of sick sinus syndrome. The association of sinus node dysfunction with malignant ventricular arrhythmia is very common. The use of antiarrhythmic drugs may aggravate the sinus node dysfunction unless a permanent pacemaker is implanted.

Ventricular premature contractions (VPCs) and intraventricular conduction disturbances are frequent and maybe predictors of early myocardial involvement (Figure 1, Panel A). VPCs can be demonstrated in about $10 \%$ of infected subjects without any other evidence of structural heart disease. ${ }^{17}$ However, the association of intraventricular conduction disturbances and abnormal ventriculogram without cardiac failure increases the risk of presenting VPCs in about $56 \%$ of cases. If cardiac failure is present, the prevalence of VPCs is about $85 \%$ and is common to detect more complex ventricular arrhythmias such as couplets, non-sustained, and sustained ventricular tachycardia. ${ }^{17}$

Electrocardiographic monitoring shows multiform VPCs, ventricular parasystole, ventricular escapes, couplets or runs of ventricular tachycardia (VT), and R on T phenomenon. VPCs with multiple morphologies are the most consistent finding. This has been attributed to the widespread foci of myocardial damage and correlates with the high prevalence of late potentials when using signal-averaged electrocardiography. ${ }^{18}$

Our group reported the initiation mode of spontaneous malignant ventricular tachyarrhythmias in 179 episodes occurring in 15 patients with $\mathrm{CChC}$ who had an implantable cardioverter defibrillator (ICD), through the analysis of stored intracardiac electrograms. A high prevalence of short-longshort sequences just before the initiation of the malignant ventricular tachyarrhythmias was observed. This motivated us to speculate in the development of specific software of the ICD in order to reduce these short-long-short sequences. ${ }^{19}$

Sudden cardiac death, usually due to ventricular fibrillation, is the most common cause of death, and its incidence is $51 \%-65 \%$ depending on the series. ${ }^{20-23}$ Malignant ventricular arrhythmias are the main cause of sudden cardiac death, followed by bradyarrhythmias (high-degree AV block) and cerebral emboli. . $^{7,24}$

The presence of nonsustained VT detected during ambulatory Holter ${ }^{25}$ monitoring and particularly during stress testing ${ }^{26}$ is a strong predictor of sudden cardiac death. Left ventricular (LV) dysfunction is also a predictor of poor outcome, particularly if associated with ventricular arrhythmias. ${ }^{8}$

Antiarrhythmic drugs in Chagas' disease: past and present Ventricular tachyarrhythmias in the setting of Chagas' disease are the most serious complications and very difficult to treat. Ventricular arrhythmias are usually unsustained but they can degenerate into malignant forms. Drug therapy is frequently ineffective to control the arrhythmia.

Almost all of the widely used antiarrhythmic agents have been used in patients with Chagas' disease. ${ }^{17}$ Unfortunately, these trials usually have been uncontrolled, noninvasively guided, or empiric, and with short-term follow-up. No drug has been shown to prolong survival in a randomized trial. In comparative studies using ambulatory electrocardiography, Haedo et $\mathrm{al}^{27}$ and Rosenbaum et $\mathrm{al}^{28}$ showed that amiodarone is the most effective of the antiarrhythmic agents and is relatively well tolerated. Patients with malignant arrhythmias treated with amiodarone and followed for 26 months with ambulatory ECG, had only few minor arrhythmic events. ${ }^{29}$ In another study ${ }^{30}$ there was a low risk of arrhythmia recurrence or death when the $\mathrm{LV}$ ejection fraction $(\mathrm{EF})$ was above $30 \%$, but there was a $100 \%$ recurrence rate and $80 \%$ mortality if patients had New York Heart Association (NYHA) class III-IV with an EF less than 30\%.

Invasively guided antiarrhythmic drug therapy seems to offer a good method for risk stratification and drug selection in patients with symptomatic sustained or non sustained VT. Sustained VT is inducible in more than $80 \%$ of patients with clinical sustained VT and in 50\% of those presenting with syncope. ${ }^{31}$

In another study, Sarabanda et al analyzed ventricular arrhythmia inducibility in patients with sustained and nonsustained VT in patients with Chagas' disease. They found induction of sustained VT by programmed ventricular stimulation in $89 \%$ of patients with clinical presentation of sustained VT and in 7\% in patients with non sustained VT. ${ }^{32}$

Leite et $\mathrm{a}^{33}$ used electrophysiologic testing to evaluate 115 patients. After loading amiodarone in 115 patients; electrophysiologic testing identified three groups: nonsustained VT was inducible (Group 1, $\mathrm{n}=23$ ); only tolerated sustained monomorphic VT was inducible (Group 2, n = 45); and nontolerated sustained monomorphic VT was inducible (Group 3, 
$\mathrm{n}=47$ ). Over a mean follow up of $52 \pm 32$ months, total mortality was significantly higher among group 3 than in groups 1 or $2 ; 29(61.7 \%), 6(26.1 \%)$, and 10 (22.2\%); (HR $10.4 ; P<0.0001)$. No significant differences in total mortality were observed between groups 1 and 2. Electrophysiologic testing can be used to stratify the risk of symptomatic patients with VT associated with $\mathrm{CChC}$; who are being treated with class III antiarrhythmic drugs.

\section{Implantable cardioverter-defibrillators in Chagas' disease}

ICDs are the first line therapeutical option for primary and secondary prevention of sudden death ${ }^{34-38}$ in the setting of coronary artery disease or nonischemic disease with depressed LV function. Because of its frequent association with sudden cardiac death, Chagas' disease has become an emerging indication for ICDs (Figure 1, Panels C and D). However the efficacy and safety in treating patients with Chagas' disease have been assessed in only few studies. ${ }^{39-41}$

Last year, we reported on the clinical impact of ICD therapy in patients with Chagas' disease treated for prevention of sudden death. ${ }^{42}$ The Medtronic ICD Registry is an international registry containing data on patients with $\mathrm{CChC}$ implanted with an ICD in Latin America. This registry includes data from patients living in Puerto Rico, the Caribbean, Mexico, and South America. All patients were implanted with a Medtronic ICD. We analyzed data from 89 patients with CChC implanted with ICD, $91 \%$ of them due to secondary prevention. After a mean follow-up of 12 months, the total mortality was $6.7 \%$. A total of 737 episodes of ventricular tachyarrhythmias in 38 patients were detected. ICD shocks were delivered in 35 episodes (4.8\%), antitachycardia pacing in 554 (75.1\%), and both in $107(13.1 \%)$. Forty one episodes $(5.6 \%)$ had spontaneous reversion. Appropriate ICD intervention rates were similar in patients presenting with sudden death $(50 \%)$, VT with hemodynamic deterioration $(50 \%)$ or without hemodynamic deterioration (47\%), or unexplained syncope (50\%).

This international registry confirmed that ICD therapy provided protection by effectively terminating lifethreatening arrhythmias in patients with Chagas' disease. This was especially so when patients were implanted due to secondary prevention purposes.

Cardinalli-Neto et $\mathrm{al}^{41}$ recently reported the largest single center experience on ICD implantation in Chagas' disease patients. They analyzed 90 patients receiving an ICD for secondary prevention. During a mean follow-up of $756 \pm 581$ days, 31 of 90 patients $(34 \%)$ died. The total mortality rates were $18 \%, 27 \%, 40 \%, 50 \%$, and $73 \%$, after $1,2,3,4$, and 5 years, respectively. The number of shocks per patient by day 30 was found to be the only independent predictor of all-cause mortality
(HR $1.86,95 \%$ CI: 1.21 to $2.86 ; P=0.005$ ). In our experience, of over 148 chagasic patients with ICD we found that age older than 65 years old (HR 2.85, CI: 1.77-3.92; $P=0.041)$ and EF less than $30 \%$ (HR 2.68, CI: $1.57-3.79 ; P=0.039$ ) were independent predictors of all cause mortality at one year. ${ }^{43}$

Chagas' disease patients receiving an ICD respond similarly to ischemic patients, ${ }^{39}$ although they tend to experience more shocks. ${ }^{44}$ Our group reported the time to occurrence of first appropriate ICD shock in 55 patients, 20 with CChC and 35 with ischemic disease. During the first 6 months of follow up, 35 of the 55 patients $(66.6 \%)$ received at least one appropriate spontaneous ICD shock; 17/20 chagasic patients ( $85 \%$ ) versus $18 / 35$ ischemic patients $(51 \%)$ received one ICD shock (RR: 1,$65 ; P<0.02)$. ${ }^{44}$ The cumulative incidence of shocks at 1,2, 3, and 6 months post-implant in chagasic patients and ischemic patients was $55 \%, 10 \%, 10 \%$, and $10 \%$ versus $14 \%, 11.5 \%, 8.5 \%$, and $17 \%$, respectively.

\section{Permanent pacemakers in Chagas' disease}

Recommendations for permanent cardiac pacing in $\mathrm{CChC}$ are similar to other diseases and were previously published. Symptoms and probably the life expectancy of patients with Chagas' disease are improved by permanent ventricular pacing. ${ }^{45}$ Recently, Vanegas reported that the main reasons for implanting a pacemaker in patients with Chagas' disease were: sinus node dysfunction (52\%); second and third degree AV block (26\%), and atrial fibrillation with AV block or trifascicular block (21\%). ${ }^{46}$

Tentori et $\mathrm{al}^{47}$ reported over 177 patients that the main causes for pacemaker implantation were: sick sinus syndrome (SSS) 32.2\%, complete AV block 41.2\%, 2:1 AV block 9.6\%, trifascicular block 4.7\%, AV block plus SSS 2.8\%, and atrial fibrillation with low ventricular response $7.2 \%$. Indication for pacing due to SSS was more prevalent in females $(43.8 \%)$ versus males $(15.9 \%) ; P<0.001$. Atrial fibrillation developed in 34 patients ( 21 with third degree AV block versus 13 with SSS, $P=0.45$ ) at a mean follow-up of 86 months post pacemaker implant.

Garcia Rincon et $\mathrm{al}^{48}$ reported that chagasic patients implanted with permanent pacemakers were younger (55 versus 68 years old; $P<0.001$ ), with lower LVEF (55 versus $60 \% ; P<0.04$ ) and with more frequent ventricular arrhythmias in Holter monitoring than implanted patients with no Chagas' disease. ${ }^{48}$

Despite sick sinus syndrome being the most frequent reason for implantation, single-chamber ventricular pacing is frequently used to treat these patients. ${ }^{46,49}$ Some economical limitations may account for this medical decision but lack of official data makes this comment purely speculative. 
The dyssynchrony induced by right apical ventricular pacing may contribute to the development of dilated cardiomyopathy in this predisposed group of patients. Dual chamber pacemakers with specific algorithms may help to minimize unnecessary ventricular pacing. Alternative sites of pacing have not been systematically studied yet.

\section{Transcatheter ablation in patients with Chagas' disease}

VT is common among patients with Chagas' disease but the ultimate mechanisms are not completely understood. Slow conduction scarred areas are related to VT arrhythmogenesis in $\mathrm{CChC}$; the $\mathrm{LV}$ inferolateral scar areas are the main source of sustained VT reentrant circuits. ${ }^{32}$

Chagasic patients tend to be younger and have higher LVEF than their counterparts with ischemic disease. It is assumed, therefore, that their prognosis is closely related to VT treatment rather than the progression of the myocardial damage caused by the disease itself. ${ }^{50} \mathrm{The} \mathrm{VT}$ recurrence rate, despite best possible treatment with amiodarone, remains high and usually poses a clinical challenge.

Radiofrequency (RF) ablation, both delivered in the endocardium and the epicardium have been demonstrated to reduce the recurrence of VT, as a single treatment or in combination with an ICD. Other sources than RF, like infrared laser, have been experimentally tested with promissory results. ${ }^{50}$

The initial reports on successful VT RF ablation in chagasic patients were reported more than 10 years ago. ${ }^{51,52}$ Since then, the evolution of the mapping techniques as well as the approach from the epicardium has expanded this technique to a larger number of patients.

In a recent study both the endocardium and epicardium of patients with CChC and VT referred for electrophysiologic study and radiofrequency ablation have been characterized. ${ }^{53}$ Seventeen patients were prospectively evaluated using a simultaneous epicardial and endocardial electroanatomical substrate mapping. With a mean of $201 \pm 94$ epicardial and $169 \pm 77$ endocardial points, the epicardial voltage areas with less or equal to $0.5 \mathrm{mV}$ were $56.8 \pm 40.6 \mathrm{~cm}^{2}$ as compared to $22.5 \pm 15.8 \mathrm{~cm}^{2}$ in the endocardium $(P=0.004)$. Analyzing the epicardial surface, there was a strong correlation between the bipolar voltage electrograms and the electrogram duration at the epicardium during sinus rhythm $(\mathrm{r}=0.897 ; P<0.0001)$. Acute success was obtained in $83.3 \%$ of patients. ${ }^{53}$

In a reported case, ablation of the mitral isthmus has also been referred to as a necessary approach to control of VT with two different morphologies that was using the isthmus as part of the circuit. ${ }^{54}$ Unfortunately, this patient presented a massive cerebral infarction that led to death. The prevention of this complication is of particular importance in chagasic patients given the higher prevalence of apical aneurysms and intracardiac thrombus.

A fairly constant finding in the reported cases is the multiple VT morphologies and cycle lengths, leading to long procedures, extensive ablations, and weaker endpoints. We speculate that as it happens in patients with ischemic VT, RF ablation in addition to an ICD may reduce the incidence of therapies delivered by the device. ${ }^{55}$

\section{Resynchronization therapy in Chagas' disease}

Cardiac resynchronization therapy (CRT) has become an established treatment for patients with moderate to severe heart failure, wide QRS complex, optimized heart failure treatment, and evidence of ventricular dyssynchrony. Randomized controlled clinical trials have shown that CRT improves NYHA functional class, exercise capacity, quality of life, and hemodynamics and reduces morbidity and mortality. ${ }^{56-59}$

Current heart failure treatment guidelines published jointly by the American College of Cardiology and the American Heart Association reflect these findings. ${ }^{60}$ They recommend CRT for patients with NYHA functional class III or ambulatory class IV heart failure who are refractory to optimal medical therapy and have sinus rhythm, a QRS duration $>120$ milliseconds, and a LVEF $<35 \%$. Although these guidelines included the presence of sinus rhythm, data from European studies suggested that patients with atrial fibrillation may also benefit from CRT if the heart rate is properly controlled. ${ }^{61}$

Careful patient selection is vital to successful CRT results. The speculation of which patients may benefit from CRT is mostly based on the results of clinical trials. No patients with $\mathrm{CChC}$ were included in these large trials.

Actually, only few papers with small numbers of patients have been published to date. Alves Fagundes et a ${ }^{162}$ recently reported their experience on CRT implantation in Chagas' disease patients. They analyzed 19 patients within a mean follow up of $24.7 \pm 20$ months. The LVEF improved from $28 \% \pm 5 \%$ to $32.2 \% \pm 11 \%$ and the NYHA functional class decreased from $3.5 \pm 0.5$ to $2.5 \pm 0.8$. No differences were found when compared with ischemic or idiopathic dilated cardiomyopathy patients.

Despite the lack of larger series, CRT is also a promising therapy for patients with $\mathrm{CChC}$ and refractory heart failure.

\section{Cell therapy in patients with Chagas' disease}

Heart transplantation is the only available option for patients with heart failure that failed optimum pharmacological and 
electrical treatment. There are several limitations to performing heart transplantation in patients with Chagas' disease, not only because its high costs and the scarcity of donated organs, but also because the need of immunosuppressive agents after transplantation that may reactivate latent infections.

The discovery of stem cells capable of differentiating into specialized cell types has opened new avenues for the treatment of heart failure due to $\mathrm{CChC}$. This therapy is able to ameliorate heart disease caused by chronic infection with Trypanosoma cruzi, repairing the heart tissue damaged by the pathological process using the patient's own cells.

Vilas-Boas et $\mathrm{al}^{63}$ published the first report on this topic in 2006. The efficacy of the therapy was evaluated in 28 patients in whom $50 \mathrm{~mL}$ of bone marrow aspirate was collected from each patient by multiple punctures of the two iliac crests. A significant improvement in several parameters during a 60 day follow-up also suggested a potential benefit of the therapy. These included improvements in NYHA functional class $(3.1 \pm 0.3$ to $1.8 \pm$ $0.5 ; P<0.0001)$, the Minnesota quality of life questionnaire $(50.9 \pm 11.7$ to $21.8 \pm 13.4 ; P<0.0001)$, the distance walked in six minutes $(355 \pm 136 \mathrm{~m}$ to $443 \pm 110 \mathrm{~m} ; P=0.003)$, and the $\operatorname{LVEF}(20.1 \pm 6.8 \%$ to $23.0 \pm 9.0 \%, P=0.02){ }^{63}$

Trainini et $\mathrm{al}^{64}$ showed their experience in five patients with cell therapy in chagasic patients with heart failure NYHA III/IV. At 17.2 \pm 8.8 months, 4 patients were alive and with NYHA I $(P<0.005)$. One patient died suddenly after 17 months of follow up. An increase of the ejection fraction was observed $(27.6 \% \pm 5.9 \%$ to $36.6 \% \pm 2.3 \% ; P<0.05)$. During the follow up no adverse events were observed in none of the patients referred for cellular implantation.

A phase III clinical trial sponsored by the Brazilian Ministry of Health is being concluded. This protocol is a double-blind placebo controlled randomized clinical trial aimed at evaluating the efficacy of bone marrow derived stem cell implants in 300 chronic chagasic Brazilian patients with dilated cardiomyopathy and heart failure NYHA III or IV. The primary endpoint of this study is to evaluate the effect of the autologous bone marrow stem cell implant in the increment of the LVEF in comparison with a control group, under optimized therapy for dilated cardiomyopathy. Secondary endpoints will evaluate the changes in NYHA functional class, mortality rate, physical capacity (by ergoespirometry), quality of life (Minnesota questionnaire), and pulmonary congestion. ${ }^{65}$

\section{Antiparasitic treatment in the "undetermined" phase: possible cardiovascular implications}

Benznidazole, a nitroimidazole derivative, has been recommended for the treatment of acute and congenital Trypanosoma cruzi infection. ${ }^{66}$ Recent data indicates that parasite persistence plays a pivotal role in the pathogenesis of chronic $\mathrm{CChC}{ }^{67}$ More recently, it has been demonstrated that the reduction of the parasite in the body may prevent the development of cardiomyopathy. ${ }^{68}$ However, the efficacy of trypanocidal therapy in preventing clinical complications in patients with preexisting cardiac disease is unknown. BENEFIT is a multicenter, randomized, double-blind, placebo-controlled clinical trial intended to recruit 3,000 patients with $\mathrm{CChC}$ in Latin America. ${ }^{69}$ BENEFIT will clarify the role of trypanocidal therapy in preventing cardiac disease progression and death. Patients will be randomized to receive benznidazole $(5 \mathrm{mg} /$ $\mathrm{kg}$ per day) or matched placebo, for 60 days. The primary outcome will be the composite of death; resuscitated cardiac arrest; sustained VT; insertion of pacemaker or ICD; cardiac transplantation; and development of new heart failure, stroke, or systemic or pulmonary thromboembolic events. The average follow-up time will be 5 years, and the trial has a $90 \%$ power to detect a $25 \%$ relative risk reduction. Recruitment started in November 2004; so far, 1,916 patients have been enrolled [Argentina (423), Brazil (987), Bolivia (191), and Colombia (315)]. ${ }^{70}$ El Salvador and Spain (Chagas' disease, as a consequence of changes in immigration patterns during the last decade, has been expanded outside South America) ${ }^{9}$ have been invited to participate and the trial is being revised by the correspondent health bodies. About $90 \%$ of the randomized patients presented heart failure NYHA class I-II and $63 \%$ had a positive basal (before treatment) PCR. A total enrollment of 2,700 patients is expected by the end of 2010 .

\section{Heart transplantation}

Indications for heart transplantation in patients with chronic heart failure secondary to $\mathrm{CChC}$ is debatable and somewhat difficult to implement, in comparison to non-Chagas' disease patients. $^{71,72}$

There have been many concerns with regard to the usefulness of heart transplantation in Chagas' disease patients due to the lack of proper indications for the procedure, the pathogenesis of the disease, the adequate immunosuppressive protocol, Trypanosoma cruzi infection reactivation, and long-term results.

Survival rates from studies following patients with severe chronic heart failure due to several etiologies indicated that patients with $\mathrm{CChC}$ and severe heart failure have a 1 year survival rate of $40 \%$ to $70 \%$, depending on the series. ${ }^{73-76}$ Another study showed 1-year survival probability is $20 \%$ in patients with NYHA IV and a LVEF $<30 \%$. $^{77}$

Recently, Dib et $\mathrm{al}^{78}$ found that patients with Chagas' disease heart failure listed for heart transplantation on inotropic support have an annual probability of mortality of $100 \%$. 
Bocchi and Fiorelli ${ }^{79}$ reported a multicentric study. They included 792 patients that underwent orthotopic heart transplantation in 16 centers in Brazil. The etiology was idiopathic dilated cardiomyopathy in 407 patients, ischemic cardiomyopathy in 196 patients, $\mathrm{CChC}$ in 117 patients, and others in 72 patients. This study showed that the probability of survival after heart transplantation in patients with CChC was at 1 year, 2 years, 6 years, and 10 years follow-up $71 \%, 62 \%, 55 \%$, and $46 \%$, respectively. Survival of chagasic recipients was significantly better in comparison with idiopathic and ischemic cardiomyopathy $(P<0.027)$. The small sample size did not allow to take definitive conclusions and these results should be confirmed with larger studies. Trypanosoma cruzi reactivations may occur after transplantation, leading to higher morbidity and graft dysfunction. Trypanosoma cruzi reactivations occurred between $27 \%$ and $39 \%$ of Chagas' disease patients. ${ }^{80}$ Bocchi et $\mathrm{al}^{79}$ surprisingly showed a low incidence of reactivation of Trypanosoma cruzi infection manifested as myocarditis and meningoencephalitis as cause of death $(0.3 \%)$. Other series with less number of patients confirmed the results obtained in this study. ${ }^{81-84}$

Heart transplantation remains controversial as a useful therapeutical option in patients with Chagas' disease.

\section{Future directions}

Chagas' disease poses a unique challenge in current medicine. The epidemiology, pathophysiology, vectors, and urgent medical interventions have been clearly identified by decades. However, only few advances in the total eradication of this disease have been made in the last years.

Why? It is a very complex, intricate problem and multifactorial in nature. Political decisions and public health policies are needed. International collaboration including economical support from developed countries may be needed to correct one of the major problems associated with this disease: poverty.

In the meantime, investigators from all around the world are contributing to the better understanding of the disease. Studies in the field of genetic interventions are ongoing. The BENEFIT study will shed light on the usefulness of antiparasitic treatment for the prevention of chronic cardiac forms.

Major advances in the comprehension and treatment of associated cardiac arrhythmias are being carried out; it is difficult to predict where we are going to be 10 years from now. We advocate for a major investment in improving housing conditions and developing public health strategies that will have a necessary impact in the current inadmissible high prevalence of Chagas' disease.

\section{Conclusions}

Chagas' disease is a serious public health problem in Central and South America. Major efforts are being implemented to control this endemic disease. Public health policies and house improving are necessary components of the changes being put into practice.

Cardiac involvement is the most frequent and serious clinical manifestation of the disease. As a result of changes in the immigration pattern, $\mathrm{CChC}$ is now encountered outside of the endemic countries, especially in the United States and Spain. Rapid recognition of this condition as well as knowing the available therapeutical options is of utmost importance for the cardiologist.

The manifestations of $\mathrm{CChC}$ are the result of progressive damage to the myocardium, extracellular matrix, cardiac autonomic innervation, and possibly the coronary microvessels. $\mathrm{CChC}$ often mimics ischemic heart disease and the commonly used noninvasive tests cannot reliably distinguish them. Prognosis depends largely on the extent of myocardial damage and is particularly poor when left ventricular dysfunction, aneurysms, or both are present. Ventricular arrhythmias in these patients are exceptionally malignant. RF ablation and ICDs became therapeutical alternatives for the treatment of these patients.

Implementing public health policies and continuing understanding the complex pathophysiology of the disease hold the promise that this fascinating and deadly disease can be controlled.

\section{Disclosure}

The authors report no conflicts of interest in this work.

\section{References}

1. World Health Organization. Control of Chagas' disease. Report of a WHO Expert Committee. Technical Report Series 811, Geneva, 1991.

2. Rosenbaum MB. Chagasic myocardiopathy. Prog Cardiovasc Dis. 1964; 7:199-225.

3. El-Sayed NM, Myler PJ, Bartholomeu DC, et al. The genome sequence of Trypanosoma cruzi, etiologic agent of Chagas disease. Science. 2005;309(5733):409-415.

4. Nunes MC, Barbosa MM, Ribeiro AL, Barbosa FB, Rocha MO. Ischemic cerebrovascular events in patients with Chagas cardiomyopathy: a prospective follow-up study. J Neurol Sci. 2009; 278(1-2):96-101.

5. Dias E, Laranja FS, Miranda A, Nobrega G. Chagas' disease: a clinical, epidemiologic and pathologic study. Circulation. 1956;14: 1035-1060.

6. Mota EA, Guimaraes AC, Santana OO, Sherlock I, Hoff R, Weller TH. A nine year prospective study of Chagas' disease in a defined rural population in northeast Brazil. Am J Trop Med Hyg. 1990; 42:429-440.

7. Aras R, de Matta JA, Mota G, Gomes I, Melo A. Cerebral infarction in autopsies of chagasic patients with heart failure. Arq Bras Cardiol. 2003;8:411-413.

8. Rassi A Jr, Rassi SG, Rassi A. Sudden death in Chagas' disease. Arq Bras Cardiol. 2001;76:75-96. 
9. Baranchuk A, Rosas F, Morillo CA. Enfermedad de Chagas en Países Desarrollados: Mito o Realidad (Chagas' disease in developed countries: myth or reality). In F Rosas, D Vanegas, and M Cabrales (eds). Enfermedad de Chagas, Bogotá, Sociedad Colombiana de Cardiología, Sociedad Española de Cardiología; 2007; p. 217-219.

10. Roberti RR, Martinez EE, Andrade JL, et al. Chagas cardiomyopathy and captopril. Eur Heart J. 1992;13:966-970.

11. Szajnbok FE, Barretto AC, Mady C, et al: Beneficial effects of enalapril on the diastolic ventricular function in Chagas myocardiopathy. Arq Bras Cardiol. 1993;60:273-278.

12. Davila DF, Angel F, Arata DB, et al. Effects of metoprolol in chagasic patients with severe congestive heart failure. Int J Cardiol. 2002;85: 255-260.

13. Botoni FA, Poole-Wilson PA, Ribeiro AL, et al: A randomized trial of carvedilol after renin-angiotensin system inhibition in chronic Chagas cardiomyopathy. Am Heart J. 2007;153:544-548.

14. Issa VS, Amaral AF, Cruz FD, et al. Beta-blocker therapy and mortality of patients with Chagas cardiomyopathy: a subanalysis of the REMADHE prospective trial. Circ Heart Fail. 2010;3:82-88.

15. Laranja FS, Dias E, Nobrega G, Miranda A. Chagas' disease. A clinical, epidemiologic and pathologic study. Circulation. 1956;14: $1035-1060$

16. Andrade ZA, Andrade SG, Oliveira G, Alonso DR. Histopathology of the conduction tissue of the heart in Chagas' myocarditis. Am Heart J. 1978;93:316-324.

17. Elizari MV, Chiale PA. Cardiac Arrhythmias in Chagas' heart disease. J Cardiovasc Electrophysiol. 1993;4:596-598.

18. Madoery C, Ruiz A, Martınez Rubio A, Madoery R. Signal-averaged electrocardiography in Chagas' disease. In: MC Tentori, L Segura, and DL Hayes (eds). Arrhythmia management in chagas' disease. New York: Futura Publishing Co. Inc., 2000: p. 67-82.

19. Rabinovich R, Muratore C, Baranchuk A Modo de inicio de las taquiarritmias ventriculares en la cardiopatía chagásica crónica. Arch Cardiol Mex. 2008;78(3):248-253.

20. Baruffa G. Contribuicao ao conhecimento da forma cronica da doenca de Chagas na zona sul do Rio Grande do Sul. $R$ AMRIGS. $1974 ; 18: 237-250$

21. Aquatella H, Catalioti F, Gomez-Mancebo JR, et al. Long-term control of Chagas disease in Venezuela: effects on serologic findings, electrocardiographic abnormalities, and clinical outcome. Circulation. 1987;76:556-562.

22. Garzon SAC, Lorga AM, Jacob JLB, et al. Predictors of mortality in chronic Chagas heart disease long-term follow up of 987 subjects for up to 22 years. J Am Coll Cardiol. 1998;31:107C.

23. Rassi A Jr, Waktare JEP, Rassi SG, et al. Chagas heart disease: long term prognostic significance of nonsustained ventricular tachycardia and lef ventricular dysfunction. PACE. 1999;22:862.

24. Coura JR, Abreu LL, Pereira JB, Willcox HP. Morbidade da doen, ca de Chagas. IV Estudo longitudinal de dez anos em Pains e Iguatama, Minas Gerais, Brasil. Mem Inst Oswaldo Cruz. 1985;80:73-80.

25. Carrasco HA, Parada H, Guerrero L, Duque M, Duran D, Molina C. Prognostic implications of clinical, electrocardiographic and hemodynamic findings in chronic Chagas' disease. Int J Cardiol. 1994;43: 27-38.

26. De Paola AA, Gomes JA, Terzian AB, Myamoto MH, Martinez Filho E. Ventricular tachycardia during exercise testing as a predictor of sudden death in patients with chronic chagasic cardiomyopathy and ventricular arrhythmias. Br Heart J. 1995;74:293-295.

27. Haedo AH, Chiale PA, Bandieri JD, Lazzari JO, Elizari MV, Rosenbaum MB. Comparative antiarrhythmic efficacy of verapamil, 17-monochloracetylajmaline, mexiletine and amiodarone in patients with severe chagasic myocarditis: relation with the underlying arrhythmogenic mechanisms. J Am Coll Cardiol. 1986;7:1114-1120.

28. Rosenbaum M, Posse R, Sgammini H, et al. Comparative multicenter clinical study of flecainide and amiodarone in the treatment of ventricular arrhythmias associated with chronic Chagas cardiopathy. Arch Inst Cardiol Mex. 1987;573:25-330.
29. Chiale PA, Halpern MS, Nau GJ, et al. Efficacy of amiodarone during long-term treatment of malignant ventricular arrhythmias in patients with chronic chagasic myocarditis. Am Heart J. 1984;107:656-665.

30. Scanavacca MI, Sosa EA, Lee JH, Bellotti G, Pileggi F. Empiric therapy with amiodarone in patients with chronic Chagas cardiomyopathy and sustained ventricular tachycardia. Arq Bras Cardiol. 1990;54: 367-371.

31. Barbosa EC, Albanesi Filho FM, Ginefra P, et al. Evaluation of syncope in patients with chronic Chagas heart disease. Arq Bras Cardiol. 1991;57:301-305.

32. Sarabanda AV, Sosa E, Simões MV, Figueiredo GL, Pintya AO, Marin-Neto JA. Ventricular tachycardia in Chagas' disease: a comparison of clinical, angiographic, electrophysiologic and myocardial perfusion disturbances between patients presenting with either sustained or nonsustained forms. Int J Cardiol. 2005;102(1):9-19.

33. Leite L, Fenelon G, Simoes A Jr, et al. Clinical usefulness of electrophysiologic testing in patients with ventricular tachycardia and chronic chagasic cardiomyopathy treated with amiodarone and sotalol. J Cardiovasc Electrophysiol. 2003;14:567-573.

34. The Antiarrhythmics Versus Implantable Defibrillator (AVID) Investigators. A comparison of antiarrhythmic-drug therapy with implantable defibrillators in patients resuscitated from near-fatal ventricular arrhythmias. N Engl J Med. 1997;337:1576-1583.

35. Connolly SJ, Gent M, Roberts RS, et al. Canadian implantable defibrillator study (CIDS): a randomized trial of the implantable cardioverter defibrillator against amiodarone. Circulation. 2000;101:1297-1302.

36. Kuck KH, Cappato R, Siebels J, Ruppel R. Randomized comparison of antiarrhythmia drug therapy with implantable defibrillators in patients resuscitated from cardiac arrest: The Cardiac Arrest Study Hamburg (CASH). Circulation. 2000;102:748-754

37. Moss AJ, Zareba W, Hall WJ, et al. Prophylactic implantation of a defibrillator in patients with myocardial infarction and reduced ejection fraction. N Engl Med J. 2002;346:877-883.

38. Bardy GH, Lee KL, Mark DB, et al. Amiodarone or an implantable cardioverter Amiodarone or an implantable cardioverter-defibrillator for congestive heart failure. $N$ Engl J Med. 2005;352:225-237.

39. Muratore C, Rabinovich R, Iglesias R, Gonzalez M, Darú V, Sosa Liprandi A. Implantable cardioverter defibrillators in patients with chagas disease: are they different from patients with coronary disease? PACE. 1997;20:194-197.

40. Cardinalli-Neto A, Greco O, Bestetti R. Automatic implantable cardioverter-defibrillators in chagas heart disease patients with malignant ventricular arrhythmias. PACE. 2006;29:467-470.

41. Cardinalli-Neto A, Bestetti R, Cordeiro J, Rodrigues V. Predictors of all-cause mortality for patients with chronic chagas heart disease receiving implantable cardioverter defibrillator therapy. J Cardiovasc Electrophysiol. 2007;18:1236-1240.

42. Muratore C, Batista Sa L, Chiale P, et al. Implantable cardioverter defibrillators and Chagas' disease: results of the ICD Registry Latin America. Europace. 2009;11(2):164-168.

43. Di Toro D, Muratore C, Aguinaga L, et al. Predictors of all-cause 1 year mortality for patients with chronic chagas 'heart disease receiving implantable cardioverter defibrillator therapy in the ICD registry. (Abstract). Accepted for presentation Heart Rhythm Society 2010.

44. Rabinovich R, Muratore C, Iglesias R, et al. Time to first shock in implantable cardioverter defibrillator (ICD) patients with Chagas cardiomyopathy. Pacing Clin Electrophysiol. 1999; 22:202-205

45. Greco OT, Ardito RV, Garzon SA, et al. Follow-up of 991 patients with multiprogrammable artificial cardiac pacemaker. Arq Bras Cardiol. 1987;49:327-331

46. Vanegas Cadavid DI. Marcapassos na doença de chagas. Rev Latino Americana MCP y Arritmias. 2008;21:70-76.

47. Tentori C, Chirife R, Ruiz A, Mazzetti H, Styglicz E, Menendez C. Long-term evaluation of patients with chronic Chagas disease and implanted cardiac pacemaker. (Abstract). Accepted for presentation Cardiostim 2010 (in press). 
48. Garcia Rincon L, Costa Rocha M, Baccarini Piris M, et al. Perfil clínico de pacientes chagásicos e não-chagásicos portadores de marca-passo cardíaco artificial. Rev Soc Bras Med Trop. 2006;39(3):245-249.

49. Costa R, Rassi A, Leao M. Estudo clínico e epidemiológico de pacientes submetidos a implante de marcapasso cardíaco artificial permanente: comparação dos portadores da doença de Chagas com os de doenças degenerativas do sistema de condução. Rev Bras Cir Cardiovasc. 2004; 19(2):107-114.

50. d'Avila A, Splinter R, Svenson RH, et al. Chagas' disease: experimental evidence of the efficacy of near infrared lasers for catheter ablation of Chagas'VT. J Interv Card Electrophysiol. 2002;7(1):23-38.

51. Rosas F, Velasco V, Arboleda F, et al. Catheter ablation of ventricular tachycardia in Chagasic cardiomyopathy. Clin Cardiol. 1997;20(2): 169-174.

52. Sosa E, Scanavacca M, D'Avila A, Bellotti G, Pilleggi F. Radiofrequency catheter ablation of ventricular tachycardia guided by nonsurgical epicardial mapping in chronic Chagasic heart disease. Pacing Clin Electrophysiol. 1999;22:128-130.

53. Henz BD, do Nascimento TA, Dietrich C, et al. Simultaneous epicardial and endocardial substrate mapping and radiofrequency catheter ablation as first-line treatment for ventricular tachycardia and frequent ICD shocks in chronic chagasic cardiomyopathy. J Interv Card Electrophysiol. 2009;26(3):195-205.

54. Scanavacca M, Sosa E, d'Avila A, De Lourdes Higuchi M. Radiofrequency ablation of sustained ventricular tachycardia related to the mitral isthmus in Chagas' disease. Pacing Clin Electrophysiol. 2002;25(3):368-371.

55. Reddy VY, Reynolds MR, Neuzil P, et al. Prophylactic catheter ablation for the prevention of defibrillator therapy. NEngl J Med. 2007;357: 2657-2665.

56. St John Sutton MG, Plappert T, Abraham WT, et al. Effect of cardiac resynchronization on left ventricular size and function in chronic heart failure. Circulation. 2003;107:1985-1990.

57. Abraham WT, Young JB, LeónAR, et al. Effects of cardiac resynchronization on disease progression in patients with left ventricular systolic dysfunction, an indication for implantable cardioverter-defibrillator, and mildly symptomatic chronic heart failure. Circulation. 2004;110:2864-2868.

58. Bristow MR, Saxon LA, Boehmer J, et al. Cardiac-resynchronization therapy with or without an implantable defibrillator in advanced chronic heart failure. N Engl J Med. 2004;350:2140-2150.

59. Cleland JGF, Daubert JC, Erdmann E, et al. The effect of cardiac resynchronization on morbidity and mortality in heart failure. $N$ Engl J Med. 2005;352:1539-1549.

60. Epstein A, DiMarco J, Ellenbogen K, et al. ACC/AHA/HRS 2008 guidelines for device-based therapy of cardiac rhythm abnormalities: a report of the American College of Cardiology/American Heart Association Task Force on Practice Guidelines. Circulation. 2008;117:e350-e408.

61. Upadhyay G, Choudhry N, Auricchio A, et al. Cardiac resynchronization in patients with atrial fibrillation. J Am Coll Cardiol. 2008;52: 1239-1246.

62. Alves Fagundes A, Latado Braga A, Pereira Magalhaes L, et al. Impacto da terapia de ressincronizacao cardíaca na cardiopatía chagásica. Rev Latino Americana MCP y Arritmias. 2009;22(4):243.

63. Vilas-Boas F, Feitosa GS, Soares MB, et al. Early results of bone marrow cell transplantation to the myocardium of patients with heart failure due to Chagas disease. Arq Bras Cardiol. 2006;87:159-166.

64. Trainini JC, Barisani JL, Lago N, et al. Resultados alejados del implante miocárdico de células madre en la miocardiopatía chagásica Rev. Argent. Cardiol. 2007;75:257-263.

65. Clinical Trials. Cell therapy in Changes cardiomyopathy. 2010. Available from: http//www.clinicaltrials.gov/ct2/show/NCT00349271. Accessed on May 1, 2010.

Vascular Health and Risk Management

\section{Publish your work in this journal}

Vascular Health and Risk Management is an international, peerreviewed journal of therapeutics and risk management, focusing on concise rapid reporting of clinical studies on the processes involved in the maintenance of vascular health; the monitoring, prevention and treatment of vascular disease and its sequelae; and the involvement of
66. Caldas IS, Talvani A, Caldas S, et al. Benznidazole therapy during acute phase of Chagas disease reduces parasite load but does not prevent chronic cardiac lesions. Parasitol Res. 2008;103(2):413-421.

67. Marin-Neto JA, Cunha-Neto E, Maciel BC, Simoes MV. Pathogenesis of chronic chagas heart disease. Circulation. 2007;115:1109-1123.

68. Garcia S, Ramos CO, Senra JFV, et al. Treatment with benznidazole during the chronic phase of experimental chagas' disease decreases cardiac alterations. Antimicrob Agents and Chemother. 2005;49:1521-1528.

69. Marin-Neto JA, Rassi A Jr, Morillo CA, et al; BENEFIT Investigators. Rationale and design of a randomized placebo-controlled trial assessing the effects of etiologic treatment in Chagas' cardiomyopathy: the BENznidazole Evaluation For Interrupting Trypanosomiasis (BENEFIT). Am Heart J. 2008;156(1):37-43.

70. Personal communication (Dr. Carlos A. Morillo), Jan 9th, 2010.

71. Aaronson KD, Schwartz JS, Chen TM, et al. Development and prospective validation of a clinical index to predict survival in ambulatory patients referred for cardiac transplant evaluation. Circulation. 1997;95:2660-2667.

72. Mehra NR, Kobashigawa J, Starling R, et al. Listing criteria for heart transplantation: International Society for Heart and Lung Transplantation guidelines for the care of cardiac transplant candidates 2006. J Heart Lung Transplant. 2006;25:1024-1042.

73. Franciosa JA, Wilen M, Ziesche S, Cohn JN. Survival in men with severe chronic left ventricular failure due to either coronary heart disease or idiopathic dilated cardiomyopathy. Am J Cardiol. 1983;51:831-836.

74. Wilson JR, Schwartz JS, St John Sutton M, et al. Prognosis in severe heart failure: relation to hemodynamic measurements and ventricular ectopic activity. J Am Coll Cardiol. 1983;2:403-410.

75. Fuster V, Gersh BJ, Giuliani ER, Tajik AJ, Brandenburg RO, Frye RL. The natural history of idiopathic dilated cardiomyopathy. Am J Cardiol. 1981;47:525-531.

76. Bertolino ND, Villafanha DF, Cardinalli-Neto A, et al. Prognostic impact of Chagas' disease in patients awaiting heart transplantation. J Heart Lung Transplant. 2010;29(4):449-453.

77. Mady C, Cardoso RH, Barreto AC, et al. Survival and predictors of survival in patients with congestive heart failure due to Chagas' cardiomyopathy. Circulation. 1994;90:3098-3102.

78. Dib JA, Bestetti RB, Freitas PF, et al. Predictors of all-cause mortality for patients with Chagas' cardiomyopathy listed for heart transplantation. Int J Cardiol. 2009;136(2):162-164.

79. Bocchi EA, Fiorelli A. The paradox of survival results after heart transplantation for cardiomyopathy caused by Trypanosoma cruzi. Ann Thorac Surg. 2001;71:1833-1838.

80. Campos SV, Strabelli TM, Amato Neto V, et al. Risk factors for Chagas' disease reactivation after heart transplantation. J Heart Lung Transplant. 2008;27(6):597-602.

81. Godoy HL, Guerra CM, Viegas RF, et al. Infections in heart transplant recipients in Brazil: the challenge of Chagas' disease. J Heart Lung Transplant. 2010;29(3):286-290.

82. Bocchi EA, Bellotti G, Mocelin A, et al. Heart transplantation for chronic Chagas' heart disease. Ann Thorac Surg. 1996;61:1727-1733.

83. Carvalho VB, Souza EFL, Vila JHA, et al. Transplantation in Chagas' disease: 10 years after the initial experience. Circulation, 1996;94: 1815-1817.

84. Almeida DR, Carvalho ACC, Branco JN, et al. Chagas disease reactivation after heart transplantation: efficacy of allopurinol treatment. J Heart Lung Transplant. 1996;15:988-992. 